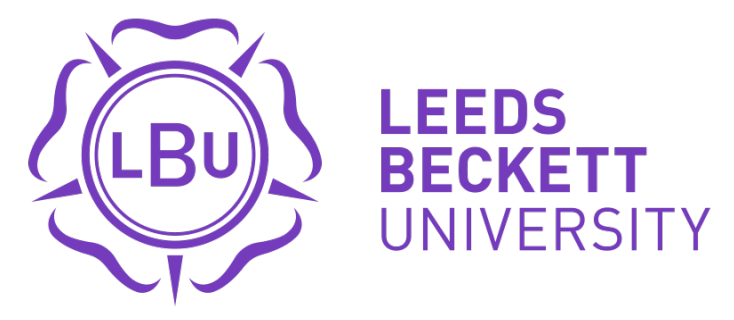

Citation:

Man, $\mathrm{K}$ and Williams, T and Barnim, $\mathrm{N}$ and Shirazipour, $\mathrm{C}$ and Latimer-Cheung, $\mathrm{A}$ and Tomasone, $\mathrm{J}$ (2020) Exploring how the process of quality participation unfolds for volunteers in community-based exercise programs for persons with disabilities. Qualitative Research in Sport, Exercise and Health. ISSN 1939-845X DOI: https://doi.org/10.1080/2159676X.2020.1727554

Link to Leeds Beckett Repository record:

https://eprints.leedsbeckett.ac.uk/id/eprint/6565/

Document Version:

Article (Accepted Version)

This is an Accepted Manuscript of an article published by Taylor \& Francis in 'Qualitative Research in Sport, Exercise and Health' on 26th February 2020, available online: https://doi.org/10.1080/2159676X.2020.1727554

The aim of the Leeds Beckett Repository is to provide open access to our research, as required by funder policies and permitted by publishers and copyright law.

The Leeds Beckett repository holds a wide range of publications, each of which has been checked for copyright and the relevant embargo period has been applied by the Research Services team.

We operate on a standard take-down policy. If you are the author or publisher of an output and you would like it removed from the repository, please contact us and we will investigate on a case-by-case basis.

Each thesis in the repository has been cleared where necessary by the author for third party copyright. If you would like a thesis to be removed from the repository or believe there is an issue with copyright, please contact us on openaccess@leedsbeckett.ac.uk and we will investigate on a case-by-case basis. 


\title{
Exploring how the process of quality participation unfolds for volunteers in community-based exercise programs for persons with disabilities
}

\author{
Kristiann E. Man ${ }^{1}$, Toni L. Williams ${ }^{2}$, Nigel Barnim ${ }^{1}$, Celina H. Shirazipour ${ }^{3}$, Amy \\ E. Latimer-Cheung ${ }^{1}$, and Jennifer R. Tomasone ${ }^{1}$
}

\author{
Affiliations: \\ ${ }^{1}$ School of Kinesiology and Health Studies, Queen's University, Kingston, Canada \\ ${ }^{2}$ Carnegie School Of Sport, Leeds-Beckett University, Leeds, United Kingdom \\ ${ }^{3}$ Research Centre for Health Equity, Cedars-Sinai Hospital, Los Angeles, United States
}

\section{ORCids:}

Jennifer R. Tomasone: https://orcid.org/0000-0003-0446-9706

Amy E. Latimer-Cheung: https://orcid.org/0000-0002-0442-6848

Celina H. Shirazipour: https://orcid.org/0000-0003-0286-1579

\section{Twitter:}

Celina H. Shirazipour: @CHShirazi

\section{Corresponding author:}

Dr. Jennifer R. Tomasone

School of Kinesiology and Health Studies, Queen's University

28 Division Street, Kingston, Ontario, Canada, K7L 3N6

Phone: 613-533-6000 x79193

E-mail: tomasone@queensu.ca

\section{Biographical details:}

Kristiann E. Man is a Master's of Science candidate in the topic of Health Promotion in the School of Kinesiology and Health Studies at Queen's University.

Toni L. Williams is a Senior Lecturer in Sport and Exercise Psychology at Leeds-Beckett University. Her research broadly explores disability, health and physical activity.

Celina H. Shirazipour is an Assistant Professor at Cedars-Sinai Medical Centre in Los Angeles.

Nigel Barnim is an undergraduate student completing a degree in the Department of Psychology at Queen's University.

Amy E. Latimer-Cheung is an Associate Professor in the School of Kinesiology and Health Studies at Queen's University. She also serves as a Canada Research Chair in Physical Activity Promotion and Disability. 
Jennifer R. Tomasone is an Assistant Professor in the School of Kinesiology and Health Studies at Queen's University. She has taught and published work concerning physical activity promotion for persons with disabilities and knowledge translation.

Data availability statement: The data that support the findings of this study are available on request from the corresponding author, JT. The data are not publicly available because they contain information that could compromise the privacy and confidentiality of research participants.

Data deposition: N/A

Supplemental online material: N/A 


\section{Exploring how the process of quality participation unfolds for volunteers in community-based exercise programs for persons with disabilities}

Within community-based exercise programs (CBEPs) for persons with disabilities, research suggests that the quality participation experiences of volunteers support the quality participation experiences of members. Yet, little is known about how quality participation unfolds over time for volunteers and how to foster positive experiences for these individuals. As such, we sought to explore how volunteers' experiences of quality participation may fluctuate over time while they are participating in a CBEP for persons with disabilities using a longitudinal, integrated methods approach. Over a five-month period, a novel combination of (a) semi-structured interviews, (b) timelines, (c) relational maps, and (d) audio diaries was used with university-aged volunteers at Revved Up, an adaptive CBEP in Kingston, Ontario. These datasets, subject to thematic analysis, illuminated meaningful understandings of how quality participation develops for volunteers by means of two overarching themes: a 'process' of how quality participation unfolds over time, and conditions supporting access to this 'process'. The findings demonstrate the value of integrating of pluralistic qualitative methods and yield insights into the quality participation process to an extent that may not have been garnered through a single method or cross-sectional study. Critical reflections and insights concerning the use of integrated methods in sport, exercise, and health fields are considered. Practically speaking, CBEP providers and researchers can utilize the findings to inform the design, implementation, and evaluation of initiatives to support the quality participation of volunteers.

Keywords: disability; exercise; volunteers; quality participation; multiple methods 


\section{Introduction}

According to the World Health Organization (2002), participation for persons with disabilities (PWD) is defined as any "involvement in life situations." Adopting this definition, much research and practice in health fields has supported a medicalized conceptualization of participation - reflecting an understanding of participation which emphasizes the quantity of involvement (e.g., the amount, duration, or frequency; Noreau et al. 2005). Yet, recent work focusing on disability indicates that an individual's subjective perceptions of participation has the potential to play a vital role in shaping prolonged involvement (Martin Ginis et al. 2017). Thus, an observable effort to promote full participation has resulted (Imms and Granlund 2014); that is, for an individual to feel like they are fully and effectively participating, not only do they need to experience agency over the amount or duration of participation (i.e., quantity), but they also need a positive subjective experience derived from participation beyond their performance (i.e., quality).

To date, there are several conceptual frameworks for understanding participation for PWD- dating back to 2008 in the occupational therapy field. Hammel and colleagues (2008) sought to conceptualize participation from the perspective of PWD, and found that there was no ideal or gold standard for optimal participation. Rather, full and effective participation appeared to manifest differently across individuals and contexts, where PWD defined and enacted full and effective participation according to their own terms. However, Hammel and colleagues (2008) still offered key participation values for consideration - all of which are underscored by the 'need for respect and dignity': (1) active and meaningful engagement/being a part of; (2) personal and societal responsibilities; (3) having an impact and supporting others; (4) social connection, inclusion, and membership; (5) access and opportunity; and (6) choice and control. 
Similarly, Moll et al. (2015) proposed the "Do-Live-Well framework" for promoting occupation, health, and well-being for PWD, suggesting eight dimensions of participation: (1) activating your body, mind and senses; (2) connecting with others; (3) contributing to community and society; (4) taking care of yourself; (5) building security/prosperity; (6) developing and expressing identity; (7) developing capabilities and potential; and (8) experiencing pleasure and joy.

While these conceptualizations are helpful for understanding the multi-dimensionality of participation, they remain limited as they cannot be applied across multiple and varying contexts (i.e., workplace, recreation, sport, exercise, family roles, etc.). Correspondingly, Martin Ginis and colleagues (2017) consolidated current understandings of participation and developed a novel conceptualization that is generalizable across such participation contexts. Their review suggests six key aspects of an individual's subjective perception of participation: (1) autonomy (e.g., independence, choice, control); (2) belongingness (e.g., a sense of belonging, acceptance); (3) challenge (e.g., feeling appropriately challenged); (4) engagement (e.g., motivation, focus); (5) mastery (e.g., achievement, competence); and (6) meaning (e.g., obtaining goals, a sense of responsibility). Since its development, Martin Ginis and colleagues' (2017) conceptualization has only been applied in the physical activity (PA) context among veteran athletes (Shirazipour et al. 2017; Shirazipour, Aiken, and Latimer-Cheung 2018; Shirazipour and Latimer-Cheung 2019), parathletes (Allan et al. 2018; Evans et al. 2018), and PWD in community-based exercise programs (CBEPs; Jackson et al. 2019).

Furthering our understanding, Evans and colleagues (2018) elaborated on quality participation as it pertains to parasport. They presented the Quality Parasport Participation Framework, which suggests that while Martin Ginis and colleagues' (2017) six quality elements hold in parasport, there are also three existing conditions types that support parathletes' access to 
experiencing quality: the physical environment (e.g., building accessibility), characteristics of the activities (e.g., type of sporting program), and social environment (e.g., the coach's role). Importantly, Evans and colleagues (2018) conceptualize quality participation as a highly individualized experience, highlighting the need to identify if and why some experiential aspects of participation may be more salient at certain times over others. As well, they advise users of the Quality Parasport Participation Framework to consider quality participation in light of several contextual factors: (a) varied value (i.e., attributing varied levels of value to different elements of quality experience); (b) varied means of achievement (i.e., using different ways to achieve each element of quality experience; (c) variation over time (i.e., attributing varied levels of value to different elements of quality experience, over time); and (d) interrelatedness (i.e., how different elements may be supported by the same event or experience).

Although Evans and colleagues' (2018) conceptualization paints a more colourful picture of quality participation in parasport, explorations of quality participation remain underwhelming among other PA contexts that have the potential to foster full and effective participation. For example, CBEPs have been identified as a viable setting to support quality participation (Jackson et al. 2019). CBEPs house knowledgeable staff and volunteers with expertise in disability, who are well versed in providing instruction, support, and accommodations for exercise, while facilitating unique PA routines that are tailored to members' specific needs and goals (Rimmer and Henley 2013). As well, CBEPs allow for one-to-one member-exercise facilitator ratios and therefore, close supervision for members (Rimmer 2012) - a role commonly fulfilled by volunteers. Indeed, Jackson and colleagues (2019) found that student volunteers are integral to the successful operation of a CBEP, and suggest that volunteers adopt supportive roles in promoting members' positive experiences. For instance, members have reported that volunteers' 
passion and positivity enhance their comfortability in a CBEP and motivate them to increase their exercise adherence (Jackson et al. 2019). Therefore, CBEPs have the potential to uphold the right to full and effective participation (United Nations Department of Public Information 2006) - not only for PWD, but for volunteers as well. However, although trends in the literature reflect a burgeoning interest in examining the PA participation of PWD in various contexts (Allan et al. 2018; Evans et al. 2018; Jackson et al. 2019; Shirazipour et al. 2017; Shirazipour and LatimerCheung 2019), very little is known about the participation experiences of volunteers, and if and how their participation impacts the quality of participation for PWD.

While much of the volunteer literature has engaged with answering what shapes volunteer action in a variety of settings (e.g., Clary, Snyder, and Stukas 1996; Griffin, and Frater 2004; Hustinx 2001; Papadakis, Planalp and Trost 2009) and the benefits of volunteerism (e.g., Casiday et al. 2008; Piliavin and Siegl 2007; Smith et al. 2010; Van Willigen 2000), research exploring volunteerism with PWD in PA domains is concentrated on short-term mega-sporting events such as the Paralympics or the Commonwealth Games through quantitative means (e.g., Baum and Lockstone 2007; Misener et al. 2015; Paradis et al. 2017). Major sporting events are one-time competitions, as opposed to community-based programming, which encompasses longterm involvement. Although such events offer opportunities for volunteers to experience development (Downward and Ralston 2006), their roles (i.e., planning, on-site support, administration and finance, venue management, etc.) and thus, quality of experience, can vary greatly from those participating in long-term community-based programming. Therefore, a multi-dimensional and holistic understanding of volunteers' participation experiences especially in community-based contexts - is lacking. While no studies to date detail volunteers' participation in CBEPs, it is plausible that they may experience satisfaction or meaning in this 
setting given they experience feelings of 'making a contribution to the community' as a result of their participation in large-scale sporting events for PWD (Giannoulakis, Wang, and Gray 2008; Surujlal 2010). As well, considering the increased dependence on volunteerism within our current society (Brennan 2005), it is important to explore what constitutes a quality participation experience for volunteers.

Whereas a number of qualitative studies have explored PA program providers (Skrastins et al. 2019), members (Richardson, Smith, and Papathomas 2017a, 2017b), or a combination of both (Adam and Morgan 2018; Jackson et al. 2019), no research thus far has exclusively examined the perspective of volunteers in CBEPs for PWD - despite the supportive role that volunteer quality participation has been seen to play in achieving member quality participation. Further, the extant work has used cross-sectional designs and single focus group or semistructured interviews, precluding an understanding of how perceptions of quality may change with ongoing participation. As Evans and colleagues (2018) have indicated, the nature of an individual's participation experience may fluctuate over time. Thus, there is merit in conducting a study to develop an in-depth understanding of these temporal nuances. In order to address this

gap in the literature, the quality participation experiences of volunteers in CBEPs for PWD must be examined. As such, the purpose of this study was to explore quality participation over time as it pertains to volunteers in a CBEP for PWD using a longitudinal, integrated methods approach.

\section{Methods}

\section{Philosophical assumptions}

This study was grounded ontologically in relativism and epistemologically in subjectivism. First, as researchers we believe there is no single reality; rather, multiple realities, which are context 
dependent and socially constructed, exist. Second, for any given reality, it is feasible that several interpretations can be made and therefore, there is no ideal process by which one's truth should be explored. From this approach, researchers' interpretations and participants' realities cannot be separated; researchers' personal values become embedded within the research process, such that they "mediate and shape what is understood" (Smith and Caddick 2012, 61). Guided by these assumptions, we embraced a pluralistic approach in our research and deployed multiple researchers and data collection techniques (Clarke, Caddick, and Frost 2016) to co-develop indepth understandings of volunteers' quality participation experiences in a CBEP for PWD.

\section{Methodological approach}

Within a single study, the fusion of multiple qualitative methods provides pluralistic datasets granting researchers access to a broad and rich collection of participant experiences which may not fully mature when using one method alone (Chamberlain et al. 2011; Williams 2018).

Echoing this, the current study used a longitudinal, integrated qualitative approach (Williams 2018; Kendellen and Camiré 2019) with a novel combination of methods: (a) semi-structured interviews, (b) timelines, (c) relational maps, and (d) audio diaries (Figure 1).

[Figure 1 here]

\section{Sampling and participants}

Revved Up is a CBEP in Kingston, Ontario, whose mission is to provide world-class, community-based exercise programming that fosters healthy living and quality of life among people living with mobility impairment, intellectual disability and/or cancer. It offers twice weekly exercise sessions to community-dwelling PWD in a one-to-one format. Revved Up has 
two streams of programming: one for members with developmental disabilities ${ }^{1}$ (e.g., autism spectrum disorder, attention deficit hyperactivity disorder, Down syndrome), and the other for members with physical disabilities ${ }^{2}$ (e.g., stroke, spinal cord injury, multiple sclerosis, Parkinson's disease). Upon enrolment, certified trainers develop personalized exercise routines for members and conduct regular assessments every six months to maintain challenge. Members are then paired with students in the Exercise, Disability and Aging internship at Queen's University or general volunteers from Queen's University. All volunteers are trained to provide assistance to members (i.e., setting up equipment, exercise instruction, offering motivational support, etc.).

We purposefully sampled undergraduate students from the two-year Exercise, Disability and Aging internship, wherein students complete the internship during their third and fourth year of undergraduate studies. Each semester, approximately 20 students are accepted into the internship following a competitive application process. Combining didactic and experiential learning opportunities, students are drawn to the enriching educational experience of the internship. In year one, students receive course credit for attending weekly seminars and completing 84 hours at Revved Up over a four month period. In year two, students become supervisors at Revved Up and oversee five gym sessions weekly, in addition to learning practical skills in program administration.

After receiving institutional ethical approval, eight students entering year one of the internship were recruited using criterion-based purposive sampling (Sparkes and Smith 2014).

\footnotetext{
${ }^{1}$ Developmental disabilities denote any type of disability characterized by limitations or impairments in physical, learning, language, or behavior areas (Boyle et al. 2011).

${ }^{2}$ Physical disabilities denote any type of disability, acquired or congenital, characterized by limitations in mobility (Statistics Canada 2017).
} 
All participants ( $n=1 \mathrm{man} ; n=7$ women) were in their third year of undergraduate studies ( $n=$ 4 Kinesiology; $n=2$ Physical Education; $n=2$ Health Studies). They varied in terms of their number of past volunteer experiences (range $=7-17$ experiences) and their experience working with PWD ( $n=2$ no experience, $n=2$ some experience, $n=4$ much experience). No participants had prior volunteer experience at Revved Up nor did any self-identify as having a disability. Part way through the internship, one participant withdrew from the study due to health reasons and was excluded from the analysis.

\section{Data collection}

\section{Interviews}

Participants completed two semi-structured interviews before and after (December 2017 and April 2018, respectively) their four month volunteering term. Semi-structured interviews were utilized as they allow for the use of prepared questions to facilitate conversation, yet enable participants to share intimate accounts of their thoughts, feelings, and experiences (Sparkes and Smith 2013). The baseline interview sought to explore participants' past volunteer experiences and expectations for volunteering at Revved Up, while the follow up interview invited them to reflect upon their participation at the CBEP.

\section{Timelines}

Timelining is a form of graphic elicitation wherein participants and researchers may collaborate to plot participants' experiences across time (Adriansen 2012; Sparkes and Smith 2013), producing temporal graphs that highlight significant life events (Sheridan, Chamberlain, and Dupuis 2011). In this study, timelining was employed in the baseline interview to gather information about each participant's past volunteer experiences (Figure 2). For each experience, further details were sought through questions pertaining to the nature of the activity (e.g., "Tell 
me more about your experience," "How did participation in this experience make you feel?", "How often did you participate in this experience?"). Data concerning volunteering frequency and duration (i.e., quantity) were integrated into the final timeline to provide complementary details to understand the quality of each experience. As Kolar et al. (2015) suggest, timelining allows participants to become engaged and experience ownership in interviews - building rapport between the interviewer and interviewee. Thus, timelines were used to supplement participants' interview responses and invite them to share rich experiences that would not otherwise have been observed through an interview alone. As well, timelines were used as a recall and comparative tool in the follow up interview to better situate each individual's participation experience at Revved Up and promote discussion.

[Figure 2 here]

\section{Relational mapping}

Relational mapping is a type of drawing task in which a participant illustrates the conceptual distance between themselves and other people or objects within their environment (Bagnoli 2009). In practice, relational mapping may be particularly helpful for participants when elaborating on multiple, complex, or abstract ideas that are potentially difficult to capture in a single interview (Crilly, Blackwell, and Clarkson 2006). We employed relational mapping in the follow up interview to add depth to participants' retrospective accounts of their participation at Revved Up (Figure 3). Participants were given necessary supplies and asked to create diagrams that visually represented their relationships with individuals at Revved Up, using spacing and line thickness to depict the closeness or intensity of relationships. In tandem, we asked participants questions exploring their rationale for their illustrative decisions (e.g., "Why is this individual close/far away from you?", and "Tell me a story about a relationship you have with 
this individual."). Using the data generated from the relational maps to extend our insights from the follow up interview, we were able to develop a understanding of volunteers' participation experiences in CBEPs beyond written and spoken word alone (Phoenix 2010; Smith and Caddick 2012).

[Figure 3 here]

\section{Audio diaries}

According to Latham (2003), audio diaries are a unique opportunity for researchers to collect participant reflections in one of the most organic fashions, given participants can interpret research questions in the context of their own lives. Indeed, audio diaries can foster a sense of safety and comfort for participants, such that they report information about phenomena that may not be otherwise accessible to researchers because of time, context, and convenience (Williamson et al. 2015). In our study, participants were asked to complete audio diaries biweekly throughout their four month volunteering term (six total). For each, participants created (e.g., using a smartphone, laptop) and uploaded a recording onto a secure online server, responding to two questions: (1) "What do you think is the most meaningful experience you had at Revved Up since your last recording and why?"; and (2) "How do you feel about the interactions you had with the Revved Up volunteers, supervisors, and members since your last recording?". Reminder emails were sent at the beginning of each data collection week. Considering the potential importance of temporality in quality participation experiences (Evans et al. 2018), audio diaries afforded us the opportunity to collect data in-the-moment and on-theground while participants were volunteering in the CBEP.

\section{Data analysis}

To preserve confidentiality, participants were assigned pseudonyms. All interview audio 
recordings and audio diaries transcribed verbatim. The completion and duration of each interview and audio diary are detailed in Table 1.

[Table 1 here]

Recognizing the recent upwelling and popularity of thematic analysis within qualitative research, as well as the critiques of its poor and confused applications (Braun and Clarke 2019), we selected thematic analysis over other techniques based on its suitability for understanding collective or shared meanings across a data set (Braun, Clarke, and Weate 2016). As Braun and Clarke (2019) comment, flexibility is one of the most appealing aspects of thematic analysis because it may be employed with a large range of research designs and data collection methods, including studies employing pluralistic approaches. When using pluralistic datasets, Chamberlain et al. (2011) suggest that the analysis and presentation of data should be fused to yield a high degree of integration. Thus, throughout our analysis, triangulation was employed in an interpretive fashion that was coherent with our philosophical assumptions. In alignment with our approach, triangulation did not seek to confirm results or certain 'truths' through secondary methods, but rather sought to illuminate the potentially contrasting and complementary aspects of the data - deepening our understanding of the given phenomenon (Natow 2019; Flick, Hirseland, and Hans 2019).

Using Braun, Clarke, and Weate's (2016) six-phase model, the lead author first entered a period of immersion, wherein she read and re-read the transcripts to note interesting features of the data and formulate initial codes. The third author then acted as a 'critical friend' to challenge such codes and their applications, contribute to the development of new codes, and stimulate reflection (Sparkes and Smith 2013). Following a second round of coding, a robust set of codes representing the analytically relevant aspects of the data was finalized. Candidate themes were 
developed by grouping codes into clusters, and were further refined and named through discussion with the critical friend. Continuing the analytic process, themes were cross referenced with each participant's transcripts (i.e., the baseline and follow up interview, and audio diaries) and within the larger dataset. The remaining co-authors, who have expertise in qualitative research, adapted PA, and/or quality participation, also acted as critical friends - prompting additional reflection and alternate understandings of the data that coloured the presentation and interpretation of the findings. Current frameworks of quality participation for PWD (e.g., Evans et al. 2018; Martin Ginis et al. 2017) were not used to develop the themes; instead, they were employed as tools to contextualize and deepen our interpretations of themes.

\section{Methodological rigour}

Aligning with a relativist approach, we did not aim for the notion of universal validity nor consult any pre-determined set criteria for quality to be applied in a universal manner (Burke 2016; Smith and McGannon 2018). Instead, relevant criteria drawing from an ongoing list of quality indicators (Levitt et al. 2017; Tracy 2010) were compiled: (a) worthiness of the topic, (b) significant contribution (e.g., enhanced understanding of quality participation for volunteers; practical application of findings to bolster the experience of volunteers in CBEPs for PWD), (c) meaningful coherence (e.g., addressing the purpose in such a way that the methods, analysis, and findings are framed within interpretivism), and (d) utility (e.g., using a longitudinal, integrated methods approach to shed light on the temporality of quality participation as it unfolds).

\section{Results}

Results are presented as two overarching themes: the process of developing quality participation over time; and the conditions supporting access to experience of the process (Figure 4). 
[Figure 4 here]

\section{The process of developing quality participation}

The first overarching theme builds a step-wise pathway by which volunteers may experience quality participation within CBEPs for PWD. The process of developing quality participation is comprised of five subthemes - purpose, motivation, progression, validation, and outcomes. There were three ways through which these subthemes unfolded: knowledge, relationships, and confidence. Quotes representing the process across knowledge, relationships, and confidence are presented in Table 2 and are summarized below.

[Table 2 near here]

Purpose

At baseline, participants identified the need to have a purpose as essential when volunteering. Specifically, the inclination to experience growth and self-improvement in their experience at a CBEP for PWD was largely discussed:

I want to learn about other people, their abilities, how people vary on the way they can exercise and how individual differences play a huge role in Revved Up ... and gain an understanding of the differences in ability for people with different disabilities, because I really don't know a lot about disabilities that exist. So I'm expecting that when I come for the first time and I get my member... I'm going to have to really learn about their disability and what kind of exercises, really look at their workout plan and make sure that I understand why they're doing the exercises. (Sylvie, knowledge, baseline interview) As expressed above, a volunteer could hold multiple purposes, simultaneously, for participation in a CBEP for PWD. For Sylvie, participation in the internship meant that she could address her curiosity for understanding disability and its implications on a person's ability to engage in PA, 
and expand her knowledge of types of disabilities. In the context of CBEPs, volunteers may also seek out participation to expand their comfortability with administering, instructing, and supporting exercise appropriate for PWD in a practical and hands-on setting.

Not only was having a purpose integral to experiencing the process of developing quality participation from the onset of participation (i.e., baseline), but participants also reported that purpose for participation could manifest at later timepoints:

The members that you interact with every week are gonna be the most meaningful because they're the people in the program that you have a direct influence on. And you're helping to improve their quality of life and ability to do things and independence and stuff like that. So I think - you can almost feel their successes with them when they go up 5 pounds and then also be sad - when my [member] regressed, it was sad for me. So, I think you become the most invested in the people that you work with most closely. (Annie, relationships, follow up interview)

Honing in on the notion of help for PWD, which has been critiqued in light of the narrative of pity and the need to 'rescue' PWD in disability literature (Bérubé 2005), Annie describes undergoing a paralleling of her emotions and desires for participation, with the member with whom she volunteers. Therefore, her purpose for volunteering transcends the idea of help for self-perceived benefits and sympathy (Piliavin and Siegl 2007; Donaldson and Prendergast 2011) and reaches one that is situated in empathy.

\section{Motivation}

Among many participants, motivation was seen as a dynamic component of the process of developing quality participation. According to Clary, Snyder, and Stukas (1996), motivations of volunteers are often underpinned by themes of functionalism (i.e., adaptive or purposeful 
strivings towards a personal or social goal, Snyder 1993); as such, to understand volunteers' purposes for involvement (e.g., to learn about disability), we must intently unravel the functions that may be served from their participation (e.g., preparing for future careers or acquiring relevant skills). Importantly, volunteers can adopt multiple motivations for participation. For example, one participant described that her involvement in a CBEP functioned as an opportunity for her to express personal values (i.e., altruism) and experience social connectedness:

Getting to know my members has been honestly one of the best parts, and makes going in so much fun each time, and I'm always really happy to get to see them and hear about their week, and especially after reading week [a mid-term break], not seeing them they were all really excited to get back in there. So that was a lot of fun to see how excited they were, and it honestly makes it all worthwhile... It makes it one of the best parts of my week. (Penny, relationships, audio diary four)

In some instances, volunteers' interests in understanding how to interact with and relate to PWD became refined; with increased knowledge of appropriate volunteer etiquette and a growing level of comfort within the CBEP, one volunteer later described how their motivation became a "passion for working with PWD” (Sylvie, relationships, audio diary five).

Another way that volunteers experienced motivation for their participation occurred when an alignment between their personal values, education, and the mission of the CBEP yielded increased esteem. When preparing for an assignment for the internship ${ }^{3}$, Annie recalled:

I thought it was super cool to get to take all of the knowledge I'd gained this year from being with [the members] in each session, to the presentations, and also from my own

\footnotetext{
${ }^{3}$ Within the internship, one of the course evaluations is a reassessment of a member's exercise program. During this evaluation, an internship student reviews a member's current routine and develops revisions (i.e., changes weight, repetitions, or minutes of exercises).
} 
background knowledge and apply it to try and improve someone's routine for the better and help them achieve their exercise goals... I think it was meaningful to realize that they really do trust us, and appreciate us there, and really enjoy us helping. (Annie, knowledge and confidence, follow up interview)

Here, Annie's comments emphasize that coupled with the educational content delivered in the internship, her practical experience in the gym supported her personal desire to help members achieve their goals. In this case, Annie's motivation for participation mirrors a considerable proportion of volunteer literature demonstrating how increases in self-esteem, self-efficacy, and social connectedness lead to enhanced perceptions of well-being (Briggs, Landry, and Wood 2007; Brown, Hoye, and Nicholson 2012).

\section{Progression}

Participants noted that experiencing progression was an important step in the process of developing quality participation. Most often, progression was linked to the three areas where growth could be experienced: knowledge, relationships, and confidence.

Volunteers explained that they experienced progress related to their knowledge of disability and PA, which was greatly supported by the educational component of the internship. For instance, because of the fluidity between learning in the classroom and practical hours in the gym setting, Annie was able to translate her knowledge:

I liked all the exercises and then even, learning in class about the different conditions and then being able to kind of pick them out in the gym and understand 'Oh, this person's exercise is - it's unilateral, maybe that's because of this.' I thought that was pretty cool to be much more knowledgeable about things. (Annie, knowledge and confidence, followup interview) 
In this quote, Annie's experience highlights experiential learning - a concept within education that draws on a "theory of experience" (Dewey 1938) - as an essential construct of progression. For Annie, Revved Up is a learning space (Kolb and Kolb 2005) whereby the her knowledge from the classroom (i.e., disability-specific considerations for exercise, contra-indications to exercise, setting up or taking down highly specialized adaptive equipment) transacts with her environment to allow the process of her learning to flourish.

In addition to knowledge, a volunteer's experience of relationship building was also a notable marker of progression. In particular, the notion of feeling known and safe with the social environment was a key tenet:

I just feel that each week I get more comfortable in the gym and closer with the supervisors, and the other volunteers and [internship] students and ... it's a very good community environment. Walking into the gym and having now, knowing all the other volunteers in my sessions and being very familiar with the members. It's very nice to walk in, say hi, see how they're doing and have that personal relationships with them. (Callie, confidence and relationships, audio diary three)

Callie describes an evolution that most volunteers echoed: over time, the volunteer environment (i.e., CBEP) changes from a foreign space where volunteers feel a sense of uncertainty or waiver in their decision making, towards a familiar and comfortable space. Of particular importance is the role of members in this development. That is, a fair number of participants felt that continued quality participation was fostered through the emergence of camaraderie, wherein an increasing "community feel" was directly related to the openness and excitement of members to work with volunteers: 
"But this week she came in and kind of waved to me and said hello and was really eager to try out the squats. So, it was exciting to see that my participation in the program had an impact on her participation and had made it easier for her to get moving." (Penny, relationships, audio diary four).

In Penny's quote, elements of cohesion start to materialize through shared focus and coexperience of progression. As participants largely spent their time with the same members, they were in the optimal position to gauge members' progress over time. Volunteers recognized the members advancing in terms of physical fitness (i.e., increased strength, balance and flexibility, aerobic capacity, etc.), and social comfortability through joking (i.e., "Someone with an electric wheelchair went in front of [the member] to go on the machines, and he whispered to me if I could guess how much his wheelchair cost - just little things like that."; Callie, relationships, follow up interview). Instead of focusing on their own progression towards their intended purpose, some participants began to share in the enjoyment and celebration of members when it became clear that they were reaching their goals. In these cases, the volunteer's progression became intertwined with member's progression; they were indistinguishable.

\section{Validation}

Participants identified validation and feedback as a helpful way for them to understand that their contributions to the CBEP were indeed meaningful. One way participants experienced validation was through receiving gratification, such as compliments, appreciation, or recognition of their efforts from others. For example, a volunteer named Walter experienced validation as he bonded with John, a member, over their mutual love of hockey:

John was like 'Oh I got these extra road hockey sticks in my garage, would you want them?...' and I was like 'Sure!' And so he brought five hockey sticks in his truck for me 
and set them out the door for me to get... And he's just like 'I'll put them outside!'... So that was really cool. You could tell he was really excited about doing it and helping me, and kind of giving that as a gift I guess. It felt really good for me too - I was like 'Wow, this guy's giving me some road hockey sticks just for coming here and working with him and having weeks with him.' (Walter, relationships, follow up interview)

In other participants' eyes, validation was captured by the concept of reciprocity. As time passed, members tended to change their demeanour around volunteers - whether it be increased responsiveness, ease of anxiousness, or relief when their paired volunteer was present:

A lot of the other volunteers or supervisors don't understand one of my members as well I can, [I] almost act as the middle man because I've spent so much time with her that I do know what she's saying - and I know when she says Trent that she means her brother, and I know how old her kids are and what they've been doing and all that kind of stuff. So I think, it seems almost like that particular member gets more relaxed when I'm there. (Annie, relationships, audio diary four)

For Annie, the time which she shared with her member facilitated her understanding of her member's disability, communication style, and life story to a level of intimacy that was not replicated by any alternative volunteer. She further reflected: "I think that experience really showed me that - how important Revved Up is to me, and just how much I love coming each session and getting to know the members. I really hope that they have the same feelings towards Revved Up and they enjoy going as much as I enjoy it." (Annie, relationships, audio diary four)

\section{Outcomes}

In their discussion of quality, volunteers described the importance of recognizing outcomes of their participation. For example, nearly all participants stated that through their participation in a 
CBEP, they developed a 'toolkit' of relevant and transferable skills to apply in future endeavours, such as a broadened understanding of disability:

Personal gains? To always never judge someone by their cover. Because it's so easy to do that, especially in the mobility impairment population, because you obviously see - right? It's visible, their disability. And there's so much more to them - they could have so many stories other than that, their disability doesn't define them. (Callie, knowledge, follow up interview)

For Callie, high contact with PWD and education through the internship program reinforced ideas of competency and acceptance of PWD. Given the pervasiveness of narratives of incompetence among PWD (Bérubé 2005; Louvet, Rohmer, and Dubois 2009), Callie's internalized perceptions towards disability may have drawn from disability-related stigma at baseline. However, as observed in sport (Kittson et al. 2013) and in PA settings (Gainforth et al. 2013), this stigma may be mitigated and PWD may be perceived to be more competent.

Volunteers also described the personal significance of participation in the CBEP perhaps the most common description capturing the meaning of volunteering at Revved Up was that it was "much more than just an exercise program." Not only was Revved Up a place to learn about disability in an interactive and enriching environment, it was a space where relationships blossomed and flourished, in-depth understandings of disability were developed, and skills ranging from social to PA spheres were honed. When exploring participants' final reflections about quality participation over time, responses moved away from being individualistic in nature, towards understanding quality participation as a built experience that was heavily contingent on the quality experience of others: 
I think that something meaningful was definitely... getting to see her [the member] grow as the weeks went on. I remember the first time she was very head-down, 'I can't do this. I haven't been able to do this exercise. I really don't want to do that warm-up.'... But then I realized she was someone who needed a little bit more motivation. There were two of us who worked with her almost every Wednesday - seeing her kind of light up when she got there, I found at the end of the 12 weeks she was doing more squats than she did at the start which I know she really didn't like. And she stopped complaining about them and was kind of excited to push herself, which was a really cool thing to see. (Penny, relationships, follow up interview)

Penny's sense of quality participation came to fruition when she understood that her member was also experiencing quality participation. When this occurred, most volunteers reported feeling even more motivated to maintain or improve their delivery of quality programming. This shared notion of quality participation between the volunteer and member also came to life through the simultaneous experience of enjoyment. Simply put, enjoyment was inherent to quality participation: "With it being one of the last weeks, I think they [members] have really showed their appreciation for what we're doing which has made it a lot more enjoyable and cool to see how much Revved Up really means to them - and how it's grown to mean a lot more for me" (Cora, relationships, audio diary six).

\section{Conditions supporting access to the process of developing quality participation}

The second overarching theme describes how the experience of quality participation can rely on conditions within environment. In particular, there are three subthemes - conditions within intrapersonal, interpersonal, and organizational levels - that support a volunteer's access to quality participation. Among these levels, conditions exist in the personal environment, social 
environment, and physical and program environment, respectively. This parallels recent work (Evans et al. 2018; Shirazipour et al. 2017, 2018) which suggests that there are certain structures in place that act as necessary support for individuals to access quality participation. Given that factors within these environments have been notably highlighted in the literature (e.g., Martin Ginis et al. 2016), the conditions for volunteers will be presented briefly (corresponding quotes in Table 3).

[Table 3 near here]

Intrapersonal level

Intrapersonal conditions drew heavily from a volunteer's life context and baseline perspectives towards participation in Revved Up, which included their attitudes and beliefs towards PWD and PA. For example, a small group of volunteers overtly expressed a lack of knowledge about disability and PA at baseline. With this awareness, these volunteers were even more sensitive and attuned to learning opportunities in the CBEP. As a result, they reported deeper reflections in their audio diaries and were able to speak to how their perspective on disability changed over time.

Another condition supporting access to quality participation was a volunteer's personal characteristics and their corresponding comfort with conversation and social interaction. Participants who either had past experiences with PWD or were outgoing in nature were better able to carry conversations with members in the CBEP. As Brown, Hoye, and Nicholson (2012) comment, high self-esteem, self-efficacy and social connectedness are important mediators for experiencing well-being in volunteers. Therefore, some volunteers accessed quality participation quicker than those who were more shy or apprehensive at the onset of their volunteering.

Interpersonal level 
The social environment in Revved Up was seen to be quite enriching: "It's just a really a very friendly place where [members] are able to complete their workouts with our help, just like how happy of a place it is... You kind of leave feeling better than when you got there" (Penny, follow up interview). Other volunteers elected to use words such as "bright" and "uplifting" to describe how the positive affect of the social environment enhanced the quality of their experiences. Notably, in support of Shirazipour et al.'s (2018) systematic review on conditions fostering quality participation for PWD, constituents of the social environment that supported quality participation for volunteers were: (a) characteristics of the members (i.e., having a group-based program); and (b) characteristics of the supervisors (i.e., having knowledgeable instructors).

Firstly, participants identified a set of member 'behaviours' or 'traits' that supported access to quality experiences. Many members arrived keen to exercise and excited to see their respective volunteer; this was a powerful social cue for participants and often set the tone for a more enjoyable exercise session. As volunteers felt less guarded, the nature of their relationships with members became increasingly relaxed: "Over the course of the month I guess she opened up more. By the end she was hilarious and was making jokes with me when she would never do that in the beginning, and she would be almost silent during the entire session" (Sylvie, follow up interview). Additionally, members who felt comfortable pointing out 'teachable moments' for volunteers facilitated volunteers' growth. Above all, when specific qualities (i.e., investment and effort, social engagement) of the volunteer were not paralleled by the member, the quality of participants' experiences degraded; conversely, when members delivered these traits, the quality of participants' experiences were bolstered.

Second, a unique feature of Revved Up is that current supervisors are graduates from the first year of the internship program. Thus, their leadership acts as a quality condition 
(Shirazipour et al. 2018) whereby they can offer mentorship and empower volunteers to navigate context-specific difficulties in the gym:

She does this thing where she'll walk around the gym to every [member] during the session to ask them how they're doing, how their day's going, if they're enjoying their exercises, and maybe something else unique to that participant. I think seeing her consistently being very intentional in doing that and the positive responses from the members definitely helped make me feel a little bit more brave. (Greta, follow up interview)

As well, using relational mapping, participants were able to pinpoint the supervisors who left memorable impressions and distinguish how their behaviours differed from less ideal supervisors. Those who consciously made themselves available by monitoring members and/or volunteers quickly developed reputations as warm, welcoming, and open-minded individuals who were eager to help. As such, participants were more willing to share thoughts and concerns with these supervisors, resulting in collaboration to make improvements to the program and to members' experiences.

\section{Organizational level}

In their discussion of quality participation, volunteers also identified quality conditions within: (a) the physical environment; and (b) the program environment. The physical environment pertained to the design of the space, access to the program and services, inclusivity within the facility, and physical safety. Participants described optimal accessibility as a place where everyone could easily get to (i.e., functional elevators, accessible parking), the gym was spacious, equipment was adaptable and available for all members, and communication was not a barrier (i.e., services available if someone was non-verbal or spoke little English). If volunteers 
observed members' basic accessibility and inclusivity needs being fulfilled, they were able to devote more attention to other aspects of their role and subsequently, were better situated to experience quality in their own participation.

From a programmatic standpoint, volunteers identified quality conditions related to the structure and organization of the CBEP. In Revved Up, the program is designed such that members attend the same pair of session each week (e.g., Monday/Wednesday 1-2 pm, etc.). However, participants' volunteering schedules are more variable, as they are determined at the beginning of the internship and dependent on their schedules. On the one hand, volunteers can be assigned to the same pair of sessions (e.g., Monday/Wednesday 1-2 pm) for the entirety of their volunteering term. In this case, the increased one-on-one contact time with the same group of members nurtures volunteers' budding acquaintances into personally meaningful connections. On the other hand, volunteers may be assigned non-paired sessions each week (e.g., Monday 1-2 $\mathrm{pm}$, and Thursday 2-3 pm), thus cultivating relationships of greater number and diversity.

Finally, the internship program required participants attended weekly seminars, which served as a confidential and non-judgemental location for volunteers to share their experiences; oftentimes, feedback and validation was given to the volunteer to commend how they dealt with a situation, and other volunteers could learn second hand how to handle similar scenarios should they arise. As well, acquiring information about adapted exercise and disability specific considerations not only deepened the resonance of Revved Up and its impact on members, but created discussion on how volunteers could further foster quality experiences for members.

\section{Discussion}


Given the limited representation of volunteers in the literature about PA for PWD, the purpose of the study was to explore the development of meaningful, quality participation experiences of volunteers over time at a CBEP. We applied a novel combination of qualitative methods and adopted an longitudinal, integrated qualitative approach (Williams 2018; Kendellen and Camiré 2019) to construct an in-depth understanding of volunteers' experiences. Importantly, the findings emphasize two key themes: first, there exists a process by which quality participation unfolds for volunteers; and second, there are conditions within the intrapersonal, interpersonal, and organizational environments that support a volunteer's access to quality participation. Together, this research contributes theoretically by advancing current conceptualizations of quality participation (Evans et al. 2018; Martin Ginis et al. 2017), methodologically through demonstrating the effectiveness of integrating multiple qualitative methods, and practically by informing the design, implementation, and evaluation of quality participation among volunteers in CBEPs for PWD.

Within the extant literature, the process of developing quality participation over time offers interesting theoretical insights. To date, research examining quality participation has focused solely on the perspective of PWD (Allan et al. 2018; Evans et al. 2018; Jackson et al. 2019; Martin Ginis et al. 2017; Shirazipour et al. 2017; Shirazipour, Aiken, and Latimer-Cheung 2018; Shirazipour and Latimer-Cheung 2019). Therefore, translating understandings of quality participation between populations must be done sensitively and with sound rationale. Here, we aim to situate our findings regarding quality participation for volunteers working with PWD amidst the published work concerning quality participation for PWD (see authors above). The process of developing quality participation can be understood as a collection of sustained, positive and meaningful experiences that persist over time. In light of Evans and colleagues' 
(2018) Quality Parasport Participation Framework recommendations (i.e., quality participation may vary across time), our findings illustrate the temporal and dynamic nature by which volunteers build their concept of quality participation over time, through the multiple subthemes within the process. Although Allan et al. $(2018,176)$ have suggested that quality participation is "varied, dynamic, and fluid over time," no process indicating how this fluidity manifests has been proposed thus far. For our participants, the subthemes of the process represented the scaffolding necessary to uphold the experience of quality participation; when volunteers identified their purpose for participation and flowed through the steps of motivation, progression, validation, and outcomes, the meaningful satisfactions derived from their work (i.e., quality participation) deepened.

Another way that the findings illuminate existing participation literature is through the 'varied means' by which volunteers experienced the subthemes of the process; that is, an individual may seek out different strategies to achieve an element of quality experience (Evans et al. 2018). Indeed, when examining how the process unfolded, volunteers reported knowledge, relationships, and confidence (Table 2) as the primary types of participation underpinning the subthemes of the process. These findings closely relate to meaning, belonging, and mastery three of the six experiential aspects of participation contributed by Martin Ginis et al. (2017). For example, when volunteers expanded their knowledge of disability and exercise for PWD, they could better understand the value of their contributions within the CBEP. Correspondingly, their perceptions of meaning were bolstered. In addition, volunteers commonly reported the emergence of genuine and fruitful relationships with others over time, and the resulting positive group environment observed at Revved Up echo the description of the experiential element of belonging. Finally, when assuming new roles in unfamiliar environments, there often exists a 
threshold of uncertainty that must be surpassed in order for an individual to feel comfortable. Over time, volunteers highlighted the upward trajectory of their perceptions of confidence as they settled into the CBEP - mirroring the experiential aspect of mastery.

When considering the second theme, conditions supporting access to the process of developing quality participation, several linkages to the literature exist. In alignment with earlier qualitative work studying participation, our findings reinforce that there are factors within the broader environment which facilitate the development of quality participation. While optimal conditions such as access and opportunity have previously been identified as constituents of participation (Hammel et al. 2008), more recent evaluations of participation in occupational therapy (Moll et al. 2015), PA for veterans (Shirazipour et al. 2017), and parasport (Evans et al. 2018) note the important distinction of conditions as structures or precursors that influence experiential aspects of participation, rather than as aspects of participation itself. Shirazipour et al. (2017) and Evans et al. (2018) have identified three key classifications, paralleled in this work, which represent conditions supporting quality participation: (1) social environment (i.e., interpersonal level); (2) physical environment (i.e., organizational level); and (3) activity or program structure (i.e., organizational level). However, although our findings mirror the classifications of the conditions, we distinguish that the conditions do not necessarily lead to the experience of a specific aspect of quality (i.e., meaning or belonging). Rather, recognizing the varied nature through which volunteers may experience quality participation, we assert that conditions are methods through which the likelihood of experiencing the process (i.e., motivation or progression) are increased.

This research also contributes novel insights into the use of multiple integrated methods in qualitative research. With rising criticisms of using 'one-shot' or 'drive-by' interviews 
(Chamberlain et al. 2011; Kendellen and Camiré 2019; Smith 2016) as a single method to capture the complexities of social phenomena, using multiple interviews over time (Josselson 2013) or combining interviews with a secondary method (i.e., observation, diaries, etc.; Gibson et al. 2013) are enticing options for researchers. According to Crozier and Cassell (2016), there exists a need to implement pluralistic and complementary methodological approaches to illuminate ambiguous processes and experiences (i.e., quality participation over time for volunteers in CBEPs for PWD). Indeed, within the current study, the fusion of methods and resulting pluralistic datasets illustrated the nuanced nature of how quality participation unfolds over time for volunteers, beyond the scope of what may have been found by any single method alone. For example, the co-development of the timelines established rapport and comfort between the interviewer and interviewee - yielding more detailed and personal stories of volunteering in the interview - and formulated a rich backdrop of experiences that the interviewer used as a comparative tool for understanding reflections of quality participation in Revved Up. Furthering our multi-dimensional understanding of quality participation, the integration of audio diaries was favourable due to its congruency with a longitudinal design. Not only can audio diaries capture developing stories in real time, but they can also provide thoughtful and unique insights concerning the personal experience of a phenomenon through a discursive think-aloud process (Monrouxe 2009). In the current study, the audio diaries were a key informant for the complex and individualized nature of how quality participation evolved over time, and offered highly contextualized, participant-directed (Latham 2003) insights on volunteers' experiences between interviews in a convenient and timely manner. Moreover, the construction of relational maps facilitated meaningful reflections that could not be prompted from questions within a single interview. Through graphic elicitation, volunteers recapitulated 
many nuances of their relationships with members, supervisors, and other volunteers through storytelling - which allowed volunteers explain and create who they were, and how they saw themselves in the CBEP during their participation experience. Thus, in the current study we have shown that the use of a longitudinal, integrated methods approach is an appropriate means to understand and further, unpack the quality participation experiences of volunteers in CBEPs for PWD.

Nonetheless, many considerations for applying this methodological approach can be noted. While Williams (2018) and Kendellen and Camiré (2019) have illustrated such considerations in-depth, we echo their sentiments briefly. When combining multiple methods, researchers commonly utilize triangulation to mitigate biases or oversights of individual methods (Gibson 2016). However, we did not deploy triangulation to produce confirmatory results; instead, triangulation was grounded in the merging of coherent and complementary methods to forge a multi-dimensional understanding of quality participation (Flick, Hirseland, and Hans 2019). As such, we support Williams' (2018) stance and ascertain that more methods does not mean new or better insights on any given topic. When debating if and how to fuse methods, researchers should deeply contemplate their study's purpose and their ontological and epistemological stance to determine whether there is sound justification for the integration of methods. For example, with the vast amount of literature in support of using diaries as tools to collect participants' intimate personal experiences, audio dairies are underrepresented as opposed to their written counterpart. When used, audio diaries have often been a method of choice for young people (Worth 2009) or PWD (Gibson et al. 2013) given its accessibility and participatory nature. However, as Worth (2009) points out, because the method is novel, one must cautiously explore the use of audio diaries and perhaps apply it with other qualitative methods. Thus, 
although there is an allure of pluralism moving forward in qualitative research, it ultimately demands time, reflexivity, and rigor in one's approach across all stages of research (Smith, Caddick, and Williams 2015).

In light of the findings, several recommendations for future practice in CBEPs for PWD can be made to improve the quality of volunteers' experiences, and members' experiences by extension. CBEPs for PWD often operate on limited budgets and time (Belza et al. 2010; Leach, Danyluk, and Culos-Reed 2014; Rimmer et al. 2004) and very few resources exist to inform how providers may optimize participation experiences of individuals volunteering or participating in their programs. Study findings begin to build the framework necessary to develop knowledge tools to support providers in changing their practice. For example, understanding how volunteers may achieve quality experiences can facilitate the delivery of more thought-provoking and resonant training modules. Noting the distinctions between how quality participation experiences manifest from individual to individual, providers may also carefully tailor volunteers' experiences so that their knowledge, confidence, or relationships with others is maximized. To this end, encouraging volunteers to engage in ongoing reflection may help them experience fulfilment from their purpose, satisfaction of their needs for motivation, progression, and validation, and meaningful outcomes of participation. Considering that intrapersonal characteristics, including sensitivity, self-awareness, and social self-efficacy, have the capacity to function as conditions supporting access to quality participation, efforts can be made to directly target such constructs. While barriers to implementation remain in CBEPs (Rimmer et al. 2004), if providers can promote and sustain quality participation experiences for volunteers, they will begin to build a faciliatory space that enhances the exercise and quality participation experiences of PWD as well. 


\section{Conclusion}

This study offers the first conceptualization of quality participation for volunteers in CBEPs for PWD. By using a novel combination of interviews, timelines, relational maps, and audio diaries over time, we have gleaned a comprehensive and multi-dimensional understanding of quality participation that both supports and extends existing frameworks describing the phenomenon. As such, coherent and thoughtful application of a longitudinal, integrated methods approach in qualitative research holds promise as we advance in the sport, exercise, and health fields.

Overall, additional research is needed to strengthen our understanding of volunteers' quality participation experiences in CBEPs for PWD, and how their participation may extend to enhance the quality experiences of members with disabilities.

\section{Acknowledgments:}

This research was supported by the Social Sciences and Humanities Research Council of Canada (SSHRC) Insight Development Grant awarded to JRT. This research was also supported by a SSHRC Joseph-Armand Bombardier Canada Graduate Scholarship awarded to KEM.

\section{Declaration of Interest Statement:}

We acknowledge that there is no financial interest or benefits that has arisen from the direct applications of our research. KEM was a former volunteer and internship student at Revved Up, and ALM and JRT are Co-Directors of Revved Up. TLW, NB, and CHD declare no conflicts of interest. 


\section{References}

Adam, S. L., and K. A. Morgan. 2018. "Meaningful Components of a Community-Based Exercise Program for Individuals with Disabilities: A Qualitative Study." Disability and Health Journal 11 (2): 301-5. https://doi.org/10.1016/j.dhjo.2017.09.001.

Adriansen, H. K. 2012. "Timeline Interviews: A Tool for Conducting Life History Research." Qualitative Studies 3 (1): 40-55. https://doi.org/10.7146/qs.v3i1.6272.

Allan, V., B. Smith, J. Côté, K. A. Martin Ginis, and A. E. Latimer-Cheung. 2018. "Narratives of Participation among Individuals with Physical Disabilities: A Life-Course Analysis of Athletes' Experiences and Development in Parasport." Psychology of Sport and Exercise 37: 170-78. https://doi.org/10.1016/j.psychsport.2017.10.004.

Bagnoli, A. 2009. "Beyond the Standard Interview: The Use of Graphic Elicitation and ArtsBased Methods." Qualitative Research 9 (5): 547-70. https://doi.org/10.1177/1468794109343625.

Baum, T., and L. Lockstone. 2007. "Volunteers and Mega Sporting Events: Developing a Research Framework." International Journal of Event Management Research 3 (1): 29-41.

Belza, B., S. Snyder, M. Thompson, and J. LoGerfo. 2010. "From Research to Practice: EnhanceFitness, an Innovative Community-Based Senior Exercise Program." Topics in Geriatric Rehabilitation 26 (4): 299-309. https://doi.org/10.1097/TGR.0b013e3181fee69e.

Bérubé, M. 2005. "Disability and Narrative." Publications of the Modern Language Association of America 120 (2): 568-76.

Boyle, C. A., S. Boulet, L. A. Schieve, R. A. Cohen, S. J. Blumberg, M. Yeargin-Allsopp, S. Visser, and M. D. Kogan. 2011. "Trends in the Prevalence of Developmental Disabilities in US Children, 1997-2008." Pediatrics 144 (4): e20190811. https://doi.org/10.1542/peds.2010-2989.

Braun, V., and V. Clarke. 2019. "Reflecting on Reflexive Thematic Analysis." Qualitative Research in Sport, Exercise and Health 11 (4): 589-97. https://doi.org/10.1080/2159676X.2019.1628806.

Braun, V., V. Clarke, and P. Weate. 2016. "Using Thematic Analysis in Sport and Exercise Research." In Routledge Handbook of Qualitative Research in Sport and Exercise, 213-27. London, UK: Routledge. https://doi.org/10.4324/9781315762012.ch15.

Brennan, M. A. 2005. "Volunteerism and Community Development: A Comparison of Factors Shaping Volunteer Behavior in Irish and American Communities." Journal of Volunteer Administration 23 (2): 20.

Briggs, E., T. D. Landry, and C. Wood. 2007. "Beyond Just Being There: An Examination of the Impact of Attitudes, Materialism, and Self-Esteem on the Quality of Helping Behavior in Youth Volunteers.” Journal of Nonprofit and Public Sector Marketing 49 (1): 91-102. https://doi.org/10.1300/J054v18n02_02.

Brown, K. M., R. Hoye, and M. Nicholson. 2012. "Self-Esteem, Self-Efficacy, and Social Connectedness as Mediators of the Relationship Between Volunteering and Well-Being." Journal of Social Service Research 38 (4): 468-83. https://doi.org/10.1080/01488376.2012.687706.

Burke, S. 2016. "Rethinking 'Validity'and 'Trustworthiness' in Qualitative Inquiry: How Might We Judge the Quality of Qualitative Research in Sport and Exercise Sciences?" In Routledge Handbook of Qualitative Research in Sport and Exercise. London, UK: Routledge. 
Canada, Statistics. 2017. "Canadian Survey on Disability 2016." Ottawa, ON.

Casiday, R., E. Kinsman, C. Fisher, and C. Bambra. 2008. "Volunteering and Health: What Impact Does It Really Have?" Volunteering England 9 (3): 1-13. https://doi.org/10.1016/j.csite.2016.11.003.

Chamberlain, K., T. Cain, J. Sheridan, and A. Dupuis. 2011. "Pluralisms in Qualitative Research: From Multiple Methods to Integrated Methods." Qualitative Research in Psychology 8 (2): 151-69. https://doi.org/10.1080/14780887.2011.572730.

Clarke, N. J., N. Caddick, and N Frost. 2016. "Pluralistic Data Analysis: Theory and Practice." In Routledge Handbook of Qualitative Research in Sport and Exercise, edited by B. Smith and A. C. Sparkes, 534-53. London, UK: Routledge.

Clary, E. G., M. Snyder, and A. A. Stukas. 1996. "Volunteers' Motivations: Findings from a National Survey." Nonprofit and Voluntary Sector Quarterly 25 (4): 485-505. https://doi.org/10.1177/0899764096254006.

Crilly, N., A. F. Blackwell, and P. J. Clarkson. 2006. “Graphic Elicitation: Using Research Diagrams as Interview Stimuli." Qualitative Research 6 (3): 341-66. https://doi.org/10.1177/1468794106065007.

Crozier, S. E., and C. M. Cassell. 2016. "Methodological Considerations in the Use of Audio Diaries in Work Psychology: Adding to the Qualitative Toolkit." Journal of Occupational and Organizational Psychology 89 (2): 396-419. https://doi.org/10.1111/joop.12132.

Dewey, J. 1938. Education and Experience. New York, NY: Simon and Schuster.

Donaldson, E., and C. Prendergast. 2011. "Introduction: Disability and Emotion 'There's No Crying in Disability Studies!'” Journal of Literary \& Cultural Disability Studies 5 (2): 129_ 35. https://doi.org/10.3828/jlcds.2011.11.

Downward, P. M., and R. Ralston. 2006. "The Sports Development Potential of Sports Event Volunteering: Insights from the XVII Manchester Commonwealth Games.” European Sport Management Quarterly 6 (4): 333-51. https://doi.org/10.1080/16184740601154474.

Evans, M. B., C. H. Shirazipour, V. Allan, M. Zanhour, S. N. Sweet, K. A. Martin Ginis, and A. E. Latimer-Cheung. 2018. "Integrating Insights from the Parasport Community to Understand Optimal Experiences: The Quality Parasport Participation Framework." Psychology of Sport and Exercise 37: 79-90. https://doi.org/10.1016/j.psychsport.2018.04.009.

Flick, U., A. Hirseland, and B. Hans. 2019. "Walking and Talking Integration: Triangulation of Data From Interviews and Go-Alongs for Exploring Immigrant Welfare Recipients' Sense(s) of Belonging." Qualitative Inquiry 25 (8): 799-810. https://doi.org/10.1177/1077800418809515.

Gainforth, H. L., D. O’Malley, T. Mountenay, and A. E. Latimer-Cheung. 2013. "Independence and Physical Activity Status Moderate Stereotypes toward People with a Physical Disability." International Journal of Sport and Exercise Psychology 11 (3): 244-57. https://doi.org/10.1080/1612197X.2013.749001.

Giannoulakis, C., C. H. Wang, and D. Gray. 2008. "Measuring Volunteer Motivation in MegaSporting Events." Event Management 11 (4): 191-200. https://doi.org/10.3727/152599508785899884.

Gibson, B. E., B. Mistry, B. Smith, K. K. Yoshida, D. Abbott, S. Lindsay, and Y. Hamdani. 2013. "The Integrated Use of Audio Diaries, Photography, and Interviews in Research with Disabled Young Men.” International Journal of Qualitative Methods 12 (1): 382-402. https://doi.org/10.1177/160940691301200118. 
Gibson, K. 2016. "Mixed-Methods Research in Sport and Exercise." In Routledge Handbook of Qualitative Research in Sport and Exercise, 404-18. London, UK: Routledge.

Hammel, J., S. Magasi, A. Heinemann, G. Whiteneck, J. Bogner, and E. Rodriguez. 2008. "What Does Participation Mean? An Insider Perspective from People with Disabilities." Disability and Rehabilitation 30 (19): 1445-60. https://doi.org/10.1080/09638280701625534.

Hustinx, L. 2001. "Individualisation and New Styles of Youth Volunteering: An Empirical Exploration." Voluntary Action 3 (2): 57-76.

Imms, C., and M. Granlund. 2014. "Participation: Are We There Yet." Australian Occupational Therapy Journal 61 (5): 291-92. https://doi.org/10.1111/1440-1630.12166.

Jackson, J., T. L. Williams, B. M. McEachern, A. E. Latimer-Cheung, and J. R. Tomasone. 2019. "Fostering Quality Experiences: Qualitative Perspectives from Program Members and Providers in a Community-Based Exercise Program for Adults with Physical Disabilities." Disability and Health Journal 12 (2): 296-301. https://doi.org/10.1016/j.dhjo.2018.11.008.

Josselson, R. 2013. "Interviewing for Qualitative Inquiry." In Interviewing for Qualitative Inquiry. Guilford Press.

Kendellen, K., and M. Camiré. 2019. "Going beyond the Interview: Methodological Considerations for 'Getting at' Life Skills Transfer Using a Longitudinal Integrated Qualitative Approach.” Qualitative Research in Sport, Exercise and Health, 1-17. https://doi.org/10.1080/2159676X.2019.1593231.

Kittson, K., H. L. Gainforth, J. Edwards, R. Bolkowy, and A. E. Latimer-Cheung. 2013. “The Effect of Video Observation on Warmth and Competence Ratings of Individuals with a Disability." Psychology of Sport and Exercise 14 (6): 847-51. https://doi.org/10.1016/j.psychsport.2013.07.003.

Kolar, K., F. Ahmad, L. Chan, and P. G. Erickson. 2015. "Timeline Mapping in Qualitative Interviews: A Study of Resilience with Marginalized Groups.” International Journal of Qualitative Methods 14 (3): 13-32. https://doi.org/10.1177/160940691501400302.

Kolb, A. Y., and D. A. Kolb. 2005. "Learning Styles and Learning Spaces: Enhancing Experiential Learning in Higher Education." Academy of Management Learning and Education 4 (2): 193-212. https://doi.org/10.5465/AMLE.2005.17268566.

Latham, A. 2003. "Research, Performance, and Doing Human Geography: Some Reflections on the Diary-Photograph, Diary-Interview Method." Environment and Planning A 35: 19932017. https://doi.org/10.1068/a3587.

Leach, H. J., J. M. Danyluk, and S. N. Culos-Reed. 2014. "Design and Implementation of a Community-Based Exercise Program for Breast Cancer Patients." Current Oncology 21 (5): 267. https://doi.org/10.3747/co.21.2079.

Levitt, H. M., S. L. Motulsky, F.J. Wertz, S. L. Morrow, and J. G. Ponterotto. 2017. "Recommendations for Designing and Reviewing Qualitative Research in Psychology: Promoting Methodological Integrity." Qualitative Psychology 4 (1): 2-22. https://doi.org/10.1037/qup0000082.

Louvet, E., O. Rohmer, and N. Dubois. 2009. "Social Judgment of People with a Disability in the Workplace. How to Make a Good Impression on Employers." Swiss Journal of Psychology 68 (3): 153-59. https://doi.org/10.1024/1421-0185.68.3.153.

Martin Ginis, K. A., M. B. Evans, W. B. Mortenson, and L. Noreau. 2017. "Broadening the Conceptualization of Participation of Persons with Physical Disabilities: A Configurative Review and Recommendations." Archives of Physical Medicine and Rehabilitation 98 (2): 395-402. https://doi.org/10.1016/j.apmr.2016.04.017. 
Martin Ginis, K. A, J. K. Ma, A. E. Latimer-Cheung, and J. H. Rimmer. 2016. “A Systematic Review of Review Articles Addressing Factors Related to Physical Activity Participation among Children and Adults with Physical Disabilities." Health Psychology Review 10 (4): 478-94. https://doi.org/10.1080/17437199.2016.1198240.

Misener, L., D. McGillivray, G. McPherson, and D. Legg. 2015. "Leveraging Parasport Events for Sustainable Community Participation: The Glasgow 2014 Commonwealth Games." Annals of Leisure Research 18 (4): 450-69. https://doi.org/10.1080/11745398.2015.1045913.

Moll, S. E., R. E. Gewurtz, T. M. Krupa, M. C. Law, N. Larivière, and M. Levasseur. 2015. "'Do-Live-Well': A Canadian Framework for Promoting Occupation, Health, and WellBeing." Canadian Journal of Occupational Therapy 82 (1): 9-23. https://doi.org/10.1177/0008417414545981.

Monrouxe, L. V. 2009. "Solicited Audio Diaries in Longitudinal Narrative Research: A View from Inside." Qualitative Research 9 (1): 81-103. https://doi.org/10.1177/1468794108098032.

Natow, R. S. 2019. "The Use of Triangulation in Qualitative Studies Employing Elite Interviews." Qualitative Research, 1-14. https://doi.org/10.1177/1468794119830077.

Noreau, Luc, Patrick Fougeyrollas, Marcel Post, and Miho Asano. 2005. "Participation after Spinal Cord Injury: The Evolution of Conceptualization and Measurement." Journal of Neurologic Physical Therapy 29 (3): 147-56. https://doi.org/10.1097/01.NPT.0000282247.15911.dc.

Papadakis, K., T. Griffin, and J. Frater. 2004. "Understanding Volunteers' Motivations.” In Proceedings of the 2004 Northeastern Recreation Research Symposium. New York, NY.

Paradis, K. F., L. J. Misener, G. McPherson, D. McGillivray, and D. Legg. 2017. "Examining the Impact of Integrated and Non-Integrated Parasport Events on Volunteer Attitudes towards Disability." Sport in Society 20 (11): 1724-44. https://doi.org/10.1080/17430437.2017.1329826.

Phoenix, C. 2010. "Seeing the World of Physical Culture: The Potential of Visual Methods for Qualitative Research in Sport and Exercise." Qualitative Research in Sport and Exercise 2 (2): 93-108. https://doi.org/10.1080/19398441.2010.488017.

Piliavin, J. A., and E. Siegl. 2007. "Health Benefits of Volunteering in the Wisconsin Longitudinal Study." Journal of Health and Social Behavior 48 (4): 450-64. https://doi.org/10.1177/002214650704800408.

Planalp, S, and M Trost. 2009. "Reasons for Starting and Continuing to Volunteer for Hospice." American Journal of Hospice and Palliative Medicine 26 (4): 288-94. https://doi.org/10.1177/1049909109333929.

Richardson, E. V., B. Smith, and A. Papathomas. 2017a. "Collective Stories of Exercise: Making Sense of Gym Experiences with Disabled Peers." Adapted Physical Activity Quarterly 34 (3): 276-94. https://doi.org/10.1123/apaq.2016-0126.

- 2017b. "Disability and the Gym: Experiences, Barriers and Facilitators of Gym Use for Individuals with Physical Disabilities.” Disability and Rehabilitation 39 (19): 1950-57. https://doi.org/10.1080/09638288.2016.1213893.

Rimmer, J. H. 2012. "Getting beyond the Plateau: Bridging the Gap between Rehabilitation and Community-Based Exercise.” Physical Medicine and Rehabilitation 4 (11): 857-61. https://doi.org/10.1016/j.pmrj.2012.08.008.

Rimmer, J. H., and K. Y. Henley. 2013. "Building the Crossroad between Inpatient/Outpatient 
Rehabilitation and Lifelong Community-Based Fitness for People with Neurologic Disability." Journal of Neurologic Physical Therapy 37 (2): 72-77.

https://doi.org/10.1097/NPT.0b013e318291bbf6.

Rimmer, J. H., B. Riley, E. Wang, A. Rauworth, and J. Jurkowski. 2004. "Physical Activity Participation among Persons with Disabilities: Barriers and Facilitators." American Journal of Preventive Medicine 26 (5): 419-25. https://doi.org/10.1016/j.amepre.2004.02.002.

Sheridan, J., K. Chamberlain, and A. Dupuis. 2011. "Timelining: Visualizing Experience." Qualitative Research 11 (5): 552-69. https://doi.org/10.1177/1468794111413235.

Shirazipour, C. H., A. B. Aiken, and A. E. Latimer-Cheung. 2018. "Exploring Strategies Used to Deliver Physical Activity Experiences to Veterans with a Physical Disability." Disability and Rehabilitation 40 (26): 3198-3205. https://doi.org/10.1080/09638288.2017.1377297.

Shirazipour, C. H., M. B. Evans, N. Caddick, B. Smith, A. B. Aiken, K. A. Martin Ginis, and A. E. Latimer-Cheung. 2017. "Quality Participation Experiences in the Physical Activity Domain: Perspectives of Veterans with a Physical Disability." Psychology of Sport and Exercise 29: 40-50. https://doi.org/10.1016/j.psychsport.2016.11.007.

Shirazipour, C. H., M. B. Evans, J. Leo, A. Lithopoulos, K. A. Martin Ginis, and A. E. LatimerCheung. 2018. "Program Conditions That Foster Quality Physical Activity Participation Experiences for People with a Physical Disability: A Systematic Review." Disability and Rehabilitation, 1-9. https://doi.org/10.1080/09638288.2018.1494215.

Shirazipour, C. H., and A. E. Latimer-Cheung. 2019. "Understanding Quality Participation:

Exploring Ideal Physical Activity Outcomes for Military Veterans with a Physical Disability." Qualitative Research in Sport, Exercise and Health, 1-16. https://doi.org/10.1080/2159676X.2019.1645037.

Skrastins, O., S. Tsotsos, H. Aqeel, A. Qiang, J. Renton, J. A. Howe, A. Tee, J. Moller, and N. M. Salbach. 2019. "Fitness Coordinators' and Fitness Instructors' Perspectives on Implementing a Task-Oriented Community Exercise Program within a HealthcareRecreation Partnership for People with Balance and Mobility Limitations: A Qualitative Study." Disability and Rehabilitation, 1-9. https://doi.org/10.1080/09638288.2019.1570357.

Smith, B., and N. Caddick. 2012. "Qualitative Methods in Sport: A Concise Overview for Guiding Social Scientific Sport Research.” Asia Pacific Journal of Sport and Social Science 1 (1): 60-73. https://doi.org/10.1080/21640599.2012.701373.

Smith, B., N. Caddick, and T. Williams. 2015. "Qualitative Methods and Conceptual Advances in Sport Psychology." In Contemporary Advances in Sport Psychology: A Review, 202-25. London, UK: Routledge.

Smith, B., and K. R. McGannon. 2018. "Developing Rigor in Qualitative Research: Problems and Opportunities within Sport and Exercise Psychology." International Review of Sport and Exercise Psychology 11 (1): 101-21. https://doi.org/10.1080/1750984X.2017.1317357.

Smith, B, and A. C. Sparkes. 2016. Routledge Handbook of Qualitative Research in Sport and Exercise. Taylor \& Francis. https://doi.org/10.4324/9781315762012.

Smith, K., K. Holmes, D. Haski-Leventhal, R. A. Cnaan, F. Handy, and J. L. Brudney. 2010. "Motivations and Benefits of Student Volunteering: Comparing Regular, Occasional, and Non-Volunteers in Five Countries." Canadian Journal of Nonprofit and Social Economy Research 1 (1). https://doi.org/10.22230/cjnser.2010v1n1a2.

Snyder, M. 1993. "Basic Research and Practical Problems: The Promise of a 'Functional' Personality and Social Psychology." Personality and Social Psychology Bulletin 19 (3): 
251-64. https://doi.org/10.1177/0146167293193001.

Sparkes, A. C., and B. Smith. 2013. Qualitative Research Methods in Sport, Exercise and Health: From Process to Product. London, UK: Routledge. https://doi.org/10.4324/9780203852187.

Surujlal, J. 2010. "Volunteer Motivation in Special Events for People with Disabilities : Sport Participation." African Journal for Physical Health Education, Recreation and Dance 13 (3): 447-61.

Tracy, S. J. 2010. "Qualitative Quality: Eight "Big-Tent" Criteria for Excellent Qualitative Research.” Qualitative Inquiry 16 (10): 837-51. https://doi.org/10.1177/1077800410383121.

United Nations Department of Public Information. 2006. "Conventions of the Rights of Persons with Disabilities." http://www.un.org/disabilities/documents/convention/convoptprot-e.pdf.

Williams, T. L. 2018. "Exploring Narratives of Physical Activity and Disability over Time: A Novel Integrated Qualitative Methods Approach.” Psychology of Sport and Exercise 37: 224-34. https://doi.org/10.1016/j.psychsport.2017.09.004.

Williamson, I., D. Leeming, S. Lyttle, and S. Johnson. 2015. "Evaluating the Audio-Diary Method in Qualitative Research." Qualitative Research Journal 15 (1): 20-34. https://doi.org/10.1108/QRJ-04-2014-0014.

Willigen, M. Van. 2000. "Differential Benefits of Volunteering across the Life Course." Journals of Gerontology - Series B Psychological Sciences and Social Sciences 55 (5): S308-18. https://doi.org/10.1093/geronb/55.5.S308.

World Health Organization. 2002. "Towards a Common Language for Functioning, Disability and Health ICF." International Classification.

Worth, N. 2009. "Making Use of Audio Diaries in Research with Young People: Examining Narrative, Participation and Audience." Sociological Research Online 14 (4): 1-11. https://doi.org/10.5153/sro.1967. 